\title{
Ethnic Stereotypes and Personality Traits in Multinational University Students
}

\author{
Irina A. Novikova, PhD \\ Peoples' Friendship University of Russia \\ Email:novikova_ia@pfur.ru \\ Alexey L. Novikov, PhD \\ 6 Miklukho-Maklay Str., Moscow, Russia, 117198 \\ Email: novikov_al@pfur.ru
}

\section{Doi:10.5901/jesr.2014.v4n2p72}

\begin{abstract}
The purpose of this paper is to consider personality traits as the factors of social perception determining the characteristics of ethnic stereotypes and prejudices in multinational university students. Based on an analysis of the published data we suppose that such personality traits as self-confidence and aggression are connected with the peculiarities of the social perception in general and ethnic perceptions in particular. A total of 95 respondents took part in the research, including 36 young men and 59 young women. All the respondents were the first, second and third year Russian students of various departments of the multinational university (PFUR). The age of the respondents is from 18 to 21 years, the average age is 19 years. The selfconfidence and aggression levels were measured by the Questionnaires developed by A. Krupnov (Krupnov, 2008) in accordance with the System-Functional Model. The features of the ethnic stereotypes of Russian students were measured by the technique of the Semantic Differential (Osgood, Suci, Tannenbaum, 1957). We used a modified version of the semantic differential called "Personal Differential" (Fetiskin, Kozlov, Manuilov, 2002). The Mann-Whitney U-test and regression analysis were used for statistical analysis. Summing up the results of the study, it can be concluded that the characteristics of the ethnic stereotypes and prejudices of the Russian students are more associated with the degree of self-confidence they have, rather than aggressiveness.
\end{abstract}

Keywords: personality traits, System-Functional Model, social perception, ethnic stereotypes, prejudices, multinational university

\section{Introduction}

In the twenty-first century the academic mobility of students is growing all over the world including Russia. So the study of various factors of cross-cultural communication and adaptation of international students is very relevant.

The study of this problem has a special importance for a multinational university such as the Peoples' Friendship University of Russia (PFUR). PFUR, established in 1961, is a unique educational space in which the representatives of about 140 countries of the world (450 peoples and nationalities) are trained. The mission of PFUR is to unite people of different nationalities, races, and religious beliefs with the help of knowledge, and also to educate youth capable of working successfully in any country of the world.

The team at the PFUR Center for personality studies has conducted a number of basic and applied studies on ethnic characteristics and personality traits, cross-cultural communication and adaptation of international students from different parts of the world (Chebotareva, 2011; Kovalenko et al; Maslova, 2011; Novikova, 2010; Novikova, Novikov, 2013 etc).

These studies are mainly based on a holistic and functional approach to analysis of personality and behavior, developed by professor Alexander Krupnov (Krupnov, 2006; Krupnov, Novikova, Kozhukhova, 2013). This approach provides the opportunity to explore not only separate aspects of some phenomenon, but whole systems, taking into account the hierarchy and interaction of their components. A number of psychodiagnostic and correctional programs have been developed in this way (Krupnov, 2008; Novikova, Belovol, 2010; Krupnov, Novikova, Kozhukhova, 2013).

Now the team at the PFUR Center for personality studies investigates the causes and prevention of ethnic tensions in a multicultural educational environment.

The purpose of this study is to consider personality traits as one of the factors determining the characteristics of ethnic stereotypes and prejudices. 
Based on an analysis of published data (Ekehammar, Akrami, Gylje, 2004), we have identified some personality characteristics that can be associated with features of social perception, for example: self-esteem, empathy, confidence in the world, self-confidence, personality traits (authoritarianism, intolerance, and aggressiveness). Therefore people with developed self-acceptance, empathy, tolerance and confidence in the world, but without the excessive self-esteem and without a tendency for authoritarianism will have a more unprejudiced perception of the communication partner.

So we suppose that such personality traits as self-confidence and aggressiveness are connected with the peculiarities of social perception in general and ethnic perceptions in particular.

In our research of self-confidence we use the System-Functional Model of organization of the personality traits developed by the professor of the PFUR A. Krupnov (Krupnov, 2006; Krupnov, Novikova, Kozhukhova, 2013). Within the framework of this approach the personality trait is studied as a complete and systematic formation. The two blocks are singled out in its structure: the motivational-meaningful, including the attitudinal-target, motivational, cognitive and productive components in its structure, and the regulatory-dynamic, containing the emotional, dynamic, regulatory, reflective-evaluative components of the personality trait. Each component contains two variables (table 1).

First of all, the motivational-meaningful provides the selection and priority of these or those incentives (sociocentric or egocentric), the depth and accuracy of the semantic values (profound or superficial awareness), the sphere of the character traits application in the subject kinds of activity (objectness) or in self-expression, self-development of the subject (subjectness). Thus the leading strategy of functioning of the given subsystem is the subject's choice of dominating senses, orientations and promptings by the principle "both this and that, but something to a greater degree".

The regulatory-dynamic subsystem represents the unity of the dynamic, emotional and regulatory variables. Thus the majority of them consists of bipolar, internally opposite (oppositional) attributes; therefore, the variables of the regulatory-dynamic subsystem are conventionally divided into "harmonious" and "non-harmonious". The basic function of this subsystem, first of all, is connected with the maintenance of regulatory-energetic basis of personality traits.

At the same time between the specified subsystems of personality traits, there exist specific relations depending on its actual/certain traits. This fact gives the grounds to assert that the indissoluble unity of these subsystems defines the specific structure and the nature of the various personality traits which ensure both the active and the adaptive functions in the communication and the activity of the subject (Krupnov, 2006; Krupnov, Novikova, Kozhukhova, 2013).

With reference to aggressiveness the system-functional model is particularized as follows (table 2). From the motivational-meaningful side the aspiration of the subject to display aggressiveness in interpersonal interaction differs in the orientation of motivation (sociocentric or egocentric), the sphere of application of the result of aggressive behavior (object or subject sphere), the level of awareness of aggressiveness as a personality property (profound or superficial). From the regulatory-dynamic side the same aspiration can be characterized by the orientation of emotional experiences (affectivity or reflectivity), by volitional regulation (internal or external), by forms of aggression manifestation (physical or verbal) and also by the character of problem situations in which aggression is shown (operational and personal difficulties).

The basic hypothesis of this study is: self-confidence and aggressiveness are connected with the peculiarities of social perception in general and ethnic perceptions in particular.

\section{Method}

The self-confidence level was measured by the Questionnaire developed by A. Krupnov (Krupnov, 2008) in accordance with the System-Functional Model (table 1). The Questionnaire consists of 8 Sections and renders possible to diagnose various components and variables of self-confidence. The Questionnaire includes 112 points: 7 questions for each variable from 16. The subject uses the quantitative scale from 1 to 7 to answer the questions.

The aggressiveness level was measured by the Questionnaire developed by A. Krupnov in accordance with the System-Functional Model (table 2) in T. Nechepurenko's modified version (Nechepurenko, 2009). The questionnaire consists of seven Sections and renders possible to diagnose various components and variables of aggressiveness. The Questionnaire includes 98 points: 7 questions for each variable from 14. The subject uses the quantitative scale from 1 to 7 to answer the questions.

The features of the ethnic stereotypes of Russian students were measured by the technique of the Semantic Differential. The semantic differential method was developed by the famous American psychologist and psycholinguist Charles Osgood (Osgood, Suci, Tannenbaum, 1957). This method allows us to identify the associations between the objects in the consciousness and the unconscious of a person.

We used a modified Russian version of the semantic differential called "Personal Differential" (Fetiskin, Kozlov, 
Manuilov, 2002). This version includes 21 bipolar scales. We asked the respondents to estimate a "typical student" from Africa, Latin America, China, and Russia on the suggested scales.

The Mann-Whitney U-test and Student's t-test for independent samples was used for statistical analysis.

A total of 95 respondents took part in the research, including 36 young men and 59 young women. All the respondents were the first, second and third year Russian students of various departments of the multinational university (PFUR). The age of the respondents is from 18 to 21 years, the average age is 19 years.

\section{Results}

At the first stage of the study, we identified the contents and the orientation of the ethnic stereotypes (Novikov, Novikova, 2011). In general, all the ethnic stereotypes are beneficial. It is very important that in the stereotypes about international students the positive qualities dominate. It is "kindness" for African students, "conscientiousness" for the Chinese students, "responsiveness" for Latin American students.

At the second stage of the study, we identified the two "extreme" groups of students differing in the orientation of their stereotypes in the sample. For this purpose, we used a statistical Mode. We conventionally named the selected group as "prejudiced" and "unprejudiced" students.

The "prejudiced" group included 16 students who have had the predominance of 1, 2, 3 point marks (the negative pole of the scale). The "unprejudiced" group included 16 students who have had the predominance of 7-point marks (the positive pole of the scale).

We compared the indicators of the self-confidence and aggressiveness variables in groups of the "prejudiced" and "unprejudiced" students (tables 3-4).

Table 3 shows that the "prejudiced" students have higher indicators of the main self-confidence variables: Sociocentric Motivation, Egocentric Motivation, Profound Awareness, Objectness, Sthenic Emotions, Asthenic Emotions, and Internal Regulation. Accordingly, the "prejudiced" students are more motivated and interested in the demonstration of confidence, while there are no differences between the groups at the behavioral level.

We suppose that the "prejudiced" students have somewhat excessive self-esteem and overconfidence. According to the literary data, excessive self-esteem may be one of the factors of a more critical attitude towards others.

In the Table 4 we can see that there is only one significant difference between the "prejudiced" and "unprejudiced" students in the indicators of the aggressiveness variables. The "unprejudiced" students have higher indicators of the Superficial Awareness of the aggressiveness.

So, the "unprejudiced" students have more superficial ideas about the aggressiveness, often interpreting it as an incorrigible trait associated with hereditary factors, etc. We assume that they will be more justified in their manifestations of aggressiveness and be more tolerant to aggressive behavior.

\section{Conclusions}

Summing up the results of the study, it can be concluded that:

1. the Russian students of the PFUR have rather favorable ethnic stereotypes about foreign students;

2. the characteristics of the ethnic stereotypes and prejudices of the students are more associated with the degree of self-confidence they have, rather than aggressiveness;

3. the obtained data should be used in the training sessions on intercultural communication and adaptation;

4. the prospects of further research is the study of other personality traits, the use of additional diagnostic and statistics methods, expanding the sample as well as conducting a similar study on a sample of the international students of the PFUR.

\section{References}

Chebotareva, E. Ju. (2011). Intercultural adaptation to Russia of students from Asia, Africa, Latin America and the Middle East. Bulletin of Peoples' Friendship University of Russia. Series: Psychology and Pedagogics, 3, 6-11.

Ekehammar, B., \& Akrami N., \& Gylje M. (2004). What matters most to prejudice: big five personality, social dominance orientation, or right-wing authoritarianism? European J. of Personality. V. 18, 463 - 482.

Fetiskin N.P., \& Kozlov V.V., \& Manuilov G.M. (2002). Social psychological diagnostics of personality and small groups development. Moscow, Russia: Institute of Psychotherapy (in Russian).

Kovalenko, A.G., \& Chebotareva, E.Yu., \& Mikheeva, N.F., \& Larina, T.V., \& Novikova, I.A., \& Ebzeeva Yu.N., \& Maslova, O.V, \& Volk, 
M.I, \& Ibadova, T.I. (2009). Intercultural Communication: Linguistic and Psychological Aspects: Collective monograph. Moscow, Russia: Peoples' Friendship Uuniversity of Russia (in Russian).

Krupnov, A.I. (2006). The system-dispositional approach to studying the personality and its properties. Bulletin of Peoples' Friendship University of Russia. Series: Psychology and Pedagogics, 1, 63-73 (in Russian).

Krupnov, A.I. (2008). Psychodiagnostics of personality traits and temperament. Moscow: MGUDT (in Russian).

Krupnov A.I., \& Novikova I.A., \& Kozhukhova Y.V.(2013) Sistem-Functional Model of Personality Traits. Academic Journal of Interdisciplinary Studies, V.2, 3, 407-413.

Maslova, O.V. (2011). Basic beliefs of personality as resource of adaptation to new culture. Bulletin of Peoples' Friendship University of Russia. Series: Psychology and Pedagogics, 3, 12-18 (in Russian)..

Nechepurenko, T.V. (2009). Gender distinctions in student's aggressiveness displays. Ph.D. Thesis. Moscow: Peoples' Friendship University of Russia (in Russian).

Novikov, A.L., \& Novikova, I.A. (2011). Semantic differential: theory and practice applications in linguistic and psychological researches. Bulletin of Peoples' Friendship University of Russia. Series: Theory of language. Semiotics. Semantics, 3, $63-71$ (in Russian).

Novikova, I.A. (2003). The problem of complex study of personality. Bulletin of Peoples' Friendship University of Russia. Series: Psychology and Pedagogics, 1, 98-107 (in Russian).

Novikova, I.A. (2010) Relationship between the parameters of tolerance and cross-cultural adaptation of international students. Bulletin of Peoples' Friendship University of Russia. Series: Psychology and Pedagogics, 4, $24-28$ (in Russian).

Novikova, I.A., \& Belovol, E.V. (2010). Complex Studies of Personality Traits: Scientific School of A.I. Krupnov. Psychological Journal, 31 (1), 135-137 (in Russian).

Novikova I.A., \& Novikov A.L. (2013) Tolerance Types and Features of Intercultural Adaptation in International Students. Journal of Educational and Social Research, V.3, 7, 625-630.

Osgood Ch.E., \& Suci G.J., \& Tannenbaum P.H. (1957). The measurement of meaning. Urbana: Univer. Illinois Press.

\section{Tables}

Table 1: The System-Functional Model of organization of the personality traits by A.I. Krupnov

\begin{tabular}{|c|c|c|}
\hline Blocks & Components & Variables \\
\hline \multirow{8}{*}{$\begin{array}{l}\text { The motivational- } \\
\text { meaningful }\end{array}$} & \multirow{2}{*}{ Attitudinal-target } & Socially Significant Purposes \\
\hline & & Personally Significant Purposes \\
\hline & \multirow{2}{*}{ Motivational } & Sociocentric Motivation \\
\hline & & Egocentric Motivation \\
\hline & \multirow{2}{*}{ Cognitive } & Profound Awareness \\
\hline & & Superficial Awareness \\
\hline & \multirow{2}{*}{ Productive } & Objectness \\
\hline & & Subjectness \\
\hline \multirow{8}{*}{ The regulatory-dynamic } & \multirow{2}{*}{ Dynamic } & Energy \\
\hline & & Inactivity \\
\hline & \multirow{2}{*}{ Emotional } & Sthenic Emotions \\
\hline & & Asthenic Emotions \\
\hline & \multirow{2}{*}{ Regulatory } & Internal Regulation \\
\hline & & External Regulation \\
\hline & \multirow{2}{*}{$\begin{array}{l}\text { Reflective- } \\
\text { evaluative }\end{array}$} & Operational Difficulties \\
\hline & & Personal Difficulties \\
\hline
\end{tabular}

Table 2: The System-Functional Model of organization of the aggressiveness by A.I. Krupnov

\begin{tabular}{|l|l|l|}
\hline Blocks & Components & Variables \\
\hline \multirow{4}{*}{ The motivational-meaningful } & Motivational & Sociocentric Motivation \\
\cline { 2 - 3 } & Cognitive & Egocentric Motivation \\
\cline { 2 - 3 } & \multirow{2}{*}{ Productive } & Profound Awareness \\
\cline { 2 - 3 } & & Superficial Awareness \\
\hline \multirow{3}{*}{ The regulatory-dynamic } & Oynamic & Subjectness \\
\hline & & Physical aggression \\
\cline { 2 - 3 } & Emotional & Verbal aggression \\
\hline
\end{tabular}




\begin{tabular}{|l|l|l|}
\hline \multirow{2}{*}{ Regulatory } & Reflectivity \\
\cline { 2 - 3 } & & Internal Regulation \\
\cline { 2 - 3 } & External Regulation \\
\cline { 2 - 3 } & Reflective-evaluative & Personal difficulties \\
\cline { 3 - 3 } & & Operational difficulties \\
\hline
\end{tabular}

Table 3: Statistical evaluation of differences in the indicators of the self-confidence between groups of the "prejudiced" and "unprejudiced" students

\begin{tabular}{|l|c|c|c|c|c|c|}
\hline \multirow{2}{*}{ Self-Confidence variables } & \multicolumn{2}{|c|}{ The "prejudiced" students (n=16) } & The "unprejudiced" students (n=16) & \multirow{2}{*}{ U-test } & P-level \\
\cline { 2 - 6 } & Mean & Sum of the ranks & Mean & Sum of the ranks & & \\
\hline Socially Significant Purposes & 34,9 & 281 & 33,1 & 247 & 111 & 0,52 \\
\hline Personally Significant Purposes & 38,9 & 292,5 & 35,9 & 235,5 & 99,5 & 0,28 \\
\hline Sociocentric Motivation & 35,8 & 345 & 29,8 & 183 & 47 & $\mathbf{0 , 0 0}$ \\
\hline Egocentric Motivation & 39,7 & $\mathbf{3 4 4 , 5}$ & $\mathbf{3 4 , 6}$ & $\mathbf{1 8 5 , 5}$ & $\mathbf{4 7 , 5}$ & $\mathbf{0 , 0 0}$ \\
\hline Profound Awareness & $\mathbf{3 7 , 3}$ & $\mathbf{3 4 3}$ & $\mathbf{3 1 , 7}$ & $\mathbf{1 8 5}$ & $\mathbf{4 9}$ & $\mathbf{0 , 0 0}$ \\
\hline Superficial Awareness & 24,0 & 293 & 21,7 & 235 & 99 & 0,27 \\
\hline Objectness & $\mathbf{3 7 , 9}$ & $\mathbf{3 1 6 , 5}$ & $\mathbf{3 3 , 0}$ & $\mathbf{2 1 1 , 5}$ & $\mathbf{7 5 , 5}$ & $\mathbf{0 , 0 4}$ \\
\hline Subjectness & 37,6 & 296,5 & 34,8 & 231,5 & 95,5 & 0,22 \\
\hline Energy & 33,1 & 280,5 & 31,8 & 247,5 & 111,5 & 0,53 \\
\hline Inactivity & 29,8 & 262,5 & 29,6 & 265,5 & 126,5 & 0,95 \\
\hline Sthenic Emotions & $\mathbf{3 7 , 3}$ & $\mathbf{3 3 5}$ & $\mathbf{3 0 , 7}$ & $\mathbf{1 9 3}$ & $\mathbf{5 7}$ & $\mathbf{0 , 0 0}$ \\
\hline Asthenic Emotions & $\mathbf{2 9 , 3}$ & $\mathbf{3 1 7 , 5}$ & $\mathbf{2 3 , 7}$ & $\mathbf{2 1 0 , 5}$ & $\mathbf{7 4 , 5}$ & $\mathbf{0 , 0 4}$ \\
\hline Internal Regulation & $\mathbf{3 4 , 9}$ & $\mathbf{3 1 6 , 5}$ & $\mathbf{3 0 , 4}$ & $\mathbf{2 1 1 , 5}$ & $\mathbf{7 5 , 5}$ & $\mathbf{0 , 0 4}$ \\
\hline External Regulation & 30,6 & 273,5 & 29,3 & 254,5 & 118,5 & 0,72 \\
\hline Operational Difficulties & 22,3 & 241 & 24,1 & 287 & 105 & 0,38 \\
\hline Personal Difficulties & 25,0 & 268,5 & 24,4 & 259,5 & 123,5 & 0,86 \\
\hline
\end{tabular}

Table 4: Statistical evaluation of differences in the indicators of the aggressiveness between groups of the "prejudiced" and "unprejudiced" students

\begin{tabular}{|l|c|c|c|c|c|c|}
\hline \multirow{2}{*}{ Aggressiveness variables } & \multicolumn{2}{|c|}{ The "prejudiced" students ( $\mathrm{n}=16)$} & \multicolumn{2}{|c|}{ The "unprejudiced" students ( $\mathrm{n}=16)$} & \multirow{2}{*}{ U-test } & P-level \\
\cline { 2 - 6 } & Mean & Sum of the ranks & Mean & Sum of the ranks & & \\
\hline Sociocentric Motivation & 26,2 & 267,5 & 25,9 & 260,5 & 124,5 & 0,89 \\
\hline Egocentric Motivation & 24,6 & 295 & 23,0 & 233 & 97 & 0,24 \\
\hline Profound Awareness & 29,4 & 286 & 28,5 & 242 & 106 & 0,40 \\
\hline Superficial Awareness & $\mathbf{2 1 , 8}$ & $\mathbf{1 8 6 , 5}$ & $\mathbf{2 7 , 7}$ & $\mathbf{3 4 1 , 5}$ & $\mathbf{5 0 , 5}$ & $\mathbf{0 , 0 0}$ \\
\hline Objectness & 25,6 & 293,5 & 23,4 & 234,5 & 98,5 & 0,26 \\
\hline Subjectness & 21,0 & 258 & 21,3 & 270 & 122 & 0,82 \\
\hline Internal Regulation & 32,4 & 248 & 33,0 & 280 & 112 & 0,54 \\
\hline External Regulation & 32,4 & 242,5 & 32,6 & 285,5 & 106,5 & 0,41 \\
\hline Physical aggression & 25,2 & 265,5 & 25,2 & 262,5 & 126,5 & 0,95 \\
\hline Verbal aggression & 33,3 & 247,5 & 33,7 & 280,5 & 111,5 & 0,53 \\
\hline Affectivity & 28,4 & 246 & 29,4 & 282 & 110 & 0,49 \\
\hline Reflectivity & 30,6 & 278,5 & 29,6 & 249,5 & 113,5 & 0,58 \\
\hline Personal difficulties & 24,8 & 248 & 26,1 & 280 & 112 & 0,54 \\
\hline Operational difficulties & 23,9 & 285 & 22,8 & 243 & 107 & 0,42 \\
\hline
\end{tabular}

\section{Appendixes}

This research was kindly supported from the Russian Foundation for the Humanities, project № 13-06-00673 ("Formation of crosscultural interaction experience in students in the system of class and extracurricular activities"). 